\title{
Morfodinámica moderna de vertientes periglaciales de alta montaña, la cuenca del Rio Cachapoal, Chile Central'.
}

\author{
María Victoria Soto Bäuerle \\ Departamento de Geografía, Universidad de Chile.mvsoto@uchile.cl \\ Carmen Paz Castro Correa \\ Departamento de Geografía, Universidad de Chile. cpcastro@uchile.cl
}

Recibido, 22 de octubre 2003 ;versión corregida y aceptada, 9 de mayo de 2005.

\begin{abstract}
RESUMEN
Se estudia los tipos de vertientes y las formas depositacionales basales correlativas en un valle alto andino de Chile Central, analizando la potencialidad de aporte de sedimentos de las vertientes y su actual condición de estabilidad. El dominio morfotéctonico del área estudiada se caracteriza por la presencia de formaciones detrítico volcánicas y sedimentarias continentales y marinas, muy tectonizadas y fuertemente plegadas. Consecuentemente, las vertientes han sido estudiadas como sistemas ligados a la estructura plegada, con variaciones en cuanto al estilo y arreglo de los estratos en una estructura monoclinal. Las formas basales de contacto correlativas a las vertientes corresponden a conos de gravedad y taludes, en diferentes estados relativos de estabilización por la vegetación. Sólo en las partes media y más alta del valle se observan depósitos gravitacionales puros actuales totalmente inconsolidados. Las diferencias encontradas en el estado actual de los depósitos de vertientes pueden ser explicadas por las diferencias de altitud y principalmente por el grado de fallamiento y de máximo plegamiento de los estratos, no siendo posible encontrar una relación clara con la litológía. Los procesos de avalancha disectan, activan y retrabajan los depósitos basales con una marcada dinámica estacional.
\end{abstract}

Palabras clave: Andes de Chile Central, sistemas de vertientes, conos de gravedad, taludes, avalanchas.

\section{Modern morphodynamics of high mountain periglacial slopes, Río Cachapoal basin, Central Chile}

\begin{abstract}
Types of slopes and correlative basal deposits are studied in an Andean high valley of Central Chile, considering the slope sediment potential supply and its stability conditions. The morphotectonic dominion is characterized by detritic-volcanic and sedimentary formations, continental and marine, which appeared high affected by tectonic forces and strongly folded. Consequently, the slopes are analyzed like systems related to the folded structure, with variations both by the style and the arrangement of the layers in a monocline structure. The slopes basal forms correspond to colluvial cones and talus, in different states of relative stabilization by vegetation. Only in the middle and higher parts of the valley, loose and consolidated pure gravitational deposits are observed. The differences founded in the present conditions of slope deposits, could be explained by the altitudinal differences and by the high level of faulting and folding of the rock layers, without to find a clear relation with the lithological composition. At the present, active avalanche processes dissect, reactivate and rework the basal deposits with a strong seasonal dynamics.
\end{abstract}

Key words: Chilean Central Andes, slope systems, colluvial cones, talus, avalanche.

1 Proyecto DID TNAC 11/2001. Universidad de Chile. 
Vertientes periglaciales alta montaña

\section{INTRODUCCION}

El contexto en que se desarrollan las vertientes periglaciales de montaña es indicado por YOUNG (1977), aunque un tratamiento más especializado puede hallarse, entre otros, en EMBLETON \& KING (1975) o en FRENCH (1976). Dentro de él, hay dos aspectos que han sido atacados, por ejemplo, en ambientes carpáticos: la zonación altitudinal y los niveles energéticos de los mecanismos como motores del modelado reciente (KOTARBA, 1984, 1992). Ello se ha aplicado a grupos de formas elaboradas en el Holoceno (BLIKRA \& NEMEC, 1998), atendiendo a los mecanismos, distinción de facies y dataciones. Los modos de asociación de las formas debidas a estos procesos pueden apreciarse en BENN \& EVANS (1998).

Con respecto a procesos y formas concretas, los movimientos en masa en las vertientes periglaciales pueden clasificarse siguiendo el esquema fundamental de SHARPE (1938, en BLOOM 1978) y anotaciones complementarias de ARAYA-VERGARA (Departamento de Geografía de la Universidad de Chile, comunicación personal). De este esquema se derivan los movimientos con creciente contenido de hielo o de nieve, pertenecientes a la categoría de los flujos, que gradan desde los de velocidad imperceptible hasta los muy rápidos.

De los flujos muy lentos (imperceptibles), los investigadores escandinavos han encontrado que la solifluxión periglacial es la menos lenta (FRENCH 1976). La naturaleza del proceso ha sido objeto de discusión por EMBLETON \& KING (1975), con respecto a la correcta aplicación del término, que debiera ser substituido por gelifluxión, concepto menos genérico, aplicado a flujos propios de ambiente periglacial. BENN \& EVANS (1998), al clasificar los movimientos en masa de acuerdo con la concentración de sedimentos y la velocidad, incluyen a la solifluxión en la base de la columna de los flujos de detritos (debris flows) como procesos dominados por friccion lenta y sobre un material viscoso. También hay observaciones acerca de reptación fría (frost creep) sobre taludes (EMBLETON \& KING, 1975). Experiencias mostradas por BLIKRA \& NEMEC (1998) indican que, siendo aún lenta, ella está regida por condiciones de inestabilidad en la tasa de transporte si la pendiente es fuerte, como ocurre en Møre-Romsdal, en Noruega occidental.

Con respecto a las formas debidas a flujos de muy alta velocidad, es bien conocida la distinción morfológica entre conos y taludes de gravedad y conos de avalancha. Se ha precisado cada vez mejor la diferencia de pendiente entre ambos: $43-45^{\circ}$ en el ápice a 20 a $30^{\circ}$ hacia la base en los de gravedad y 13 a $15^{\circ}$ para los de avalancha (BLIKRA \& NEMEC 1998). Estos autores destacan que los conos de gravedad son más cortos que los de avalancha. Pero RAPP (1960) ya demostró que las propiedades del talud dependen de varios factores, entre los que destaca la remoción local y el tipo de avalancha. Para los fenómenos de gravedad, el ancho de un talud depende también de la velocidad de caída de los materiales y esta última, de la altura de la cara libre. Esto fue observado recientemente por ARAYA-VERGARA (Departamento de Geografía, Universidad de Chile, comunicación personal) en taludes de gravedad asociados a la pared rocosa de un circo antiguo (Farellones, Andes de Santiago). Donde la cara libre es más alta, los materiales desprendidos más gruesos alcanzan mayor distancia hacia la parte distal del talud, haciéndolo más ancho.

Algunas observaciones han permitido tratar la interacción entre procesos de avalancha y gravitacionales. Se ha encontrado que hay avalanchas que tienen la capacidad de incidir los conos gravitacionales formando profundas cárcavas (BALLANTYNE \& BENN 1994); CURRY \& BALLANTYNE (1999 en CURRY 1999). BALLANTYNE (2002) observa que los depósitos de base de vertiente, de fuerte pendiente, son susceptibles de ser erosionados por flujos de detritos (debris flow), avalanchas de nieve y mecanismos asociados. Estos procesos pueden llegar a retrabajar completamente tales depósitos, removiendo extensas áreas de morrenas late- 
rales y formando paisajes paraglaciares caracterizados por la disección en cárcavas. Se relacionan con la formación de conos de base de vertiente coalescentes y depósitos de fondo de valle retrabajados por corrientes de agua.

Estudios sobre las características sedimentológicas del diamicton (textura y morfometría) han entregado herramientas para la interpretación de factores activantes, proveniencia de los materiales, su movilidad y potencial de alargamiento. (p. ej. BLIKRA \& NEMEC 1998 y MATTHEWS et al. 1999 en Noruega). Este último corresponde al runout o extensión del flujo fuera del área de origen, según la definición dada por los especialistas (J. F. ARAYA-VERGARA, Dep. de Geografía Universidad de Chile, comunicación personal).

Por su parte, las descripciones de regímenes fluviales periglaciales han indicado sus irregularidades y fluctuaciones repentinas de caudal (BLIKRA \& NEMEC, 1998). Después de prolongados períodos invernales de retención crio-nival, se liberan flujos de dimensiones catastróficas por un breve período durante la primavera o a comienzos del verano, generándose una considerable erosión y movimiento de detritos (régimen flashy, de autores anglosajones, J.F. ARAYAVERGARA, comunicación personal). Este patrón de actividad concentrada tiene mayor potencial erosivo y de transporte que un flujo distribuido más regularmente a través del año. Así, en las incidencias flash se ha encontrado que las formas fluviales y los patrones de erosión y depositación reflejan una energía suficiente para el transporte de masa (VANDENBERGHE \& WOO, 2002).

Con respecto a ambientes periglaciales de montaña chilenos (Andes de Chile Central), con asociaciones frecuentes de cara libre y talud, ARAYA-VERGARA (1985) elaboró una clasificación de vertientes, concebida como una base para la comprensión de los procesos actuales. Ésta considera a las vertientes como sistemas de elementos que se combinan comúnmente de manera compuesta o compleja. Experiencias posteriores indicaron que con este sistema puede comprenderse estructuras espaciales de formas de alta montaña en los Andes de Santiago (ARAYA-VERGARA 1996). Conjuntamente, HAUSER (1993) propuso una sistematización de remociones en masa en Chile. Observaciones de conjunto sobre valles andinos han sido dadas a conocer en CASTRO et al. (2002), SOTO \& CASTRO (2003), CASTRO et al. (2003) y SOTO et al. (2004).

Para la distinción entre taludes actuales y relictos, o la interacción entre ambos, el caso descrito en el Norte Chico de Chile por WEISCHET (1968), ha sido destacado a nivel mundial como herramienta para la construcción de la teoría correspondiente (YOUNG 1977).

Finalmente, existen observaciones sobre los depósitos de relleno cuaternario en el valle de Las Leñas (VARELA 1986), referentes probablemente a la Última Glaciación en el caso de morrenas de fondo de valle. En cambio, las formas derivadas de remociones en masa y las fluviales son atribuidas al Holoceno. Esta indicación puede ser importante para entender las influencias relictas sobre formas más recientes.

En relación con lo expuesto, el propósito de este trabajo es conocer la dinámica actual de los sistemas de vertientes a través del reconocimiento de los depósitos de base de vertiente como forma correlativa de los procesos de aporte de detritos desde las partes altas. Es importante reconocer en la dinámica actual de los sistemas de vertiente y sus depósitos basales, la acción de las avalanchas que inciden y retrabajan los taludes. 


\section{MATERIALES Y MÉTODOS}

\section{Materiales Estudiados}

\section{Emplazamiento de la cuenca en relación} con las formas características

El sector estudiado corresponde a la cuenca alta del río Cachapoal, situada entre los 1200 m.s.n.m. en el fondo de valle y los 4.500 m.s.n.m. en las altas cumbres (Fig.1). Se asume que se trata de un paisaje periglacial de montaña, porque presenta vertientes con muy frecuente asociación de cara libre y talud y formas asociadas. Estos rasgos existen en una región en que la línea de nieves moderna se ubica entre 3.000 y 4.000 m.s.n.m. y la línea de nieves pleistocena, conjeturalmente entre 2.900 y 2.000 m.s.n.m. (NOGAMI 1976). Pero estos valores, basados en altitudes de fondos de circo, provienen de referencias bibliográficas indirectas y sólo en un caso, del uso de fotos aéreas. Para adaptarse más a la realidad del terreno, hay que considerar que, frente a Santiago, la altitud más probable de los fondos de circos de la Última Glaciación es de $\sim 3.250$ m.s.n.m., mientras la de los homólogos actuales es de $\sim 4.000$ m.s.n.m. o un poco más (J. F. ARAYA-VERGARA, Dep. de Geografía Universidad de Chile, comunicación personal). Conjuntamente, ARAYAVERGARA agrega que ya a 1.700 o 1.800 m.s.n.m. de altitud, se puede observar conos de gravedad y corredores de avalanchas modernos en valles al norte y al sur del área estudiada.

\section{Estructura geológica de las caras libres abastecedoras de detritos}

La sección baja del valle está constituida de rocas sedimentarias límnicas y rocas efusivas y piroclásticas (KLOHN, 1960). Las dislocaciones se caracterizan por un intenso fallamiento y plegamiento (CHARRIER et al. 1997). En la sección media de la cuenca se presentan de manera muy localizada rocas sedimentarias marinas (KLOHN, 1960). Su composición consiste en calizas compactas, areniscas calcáreas finas y algunas

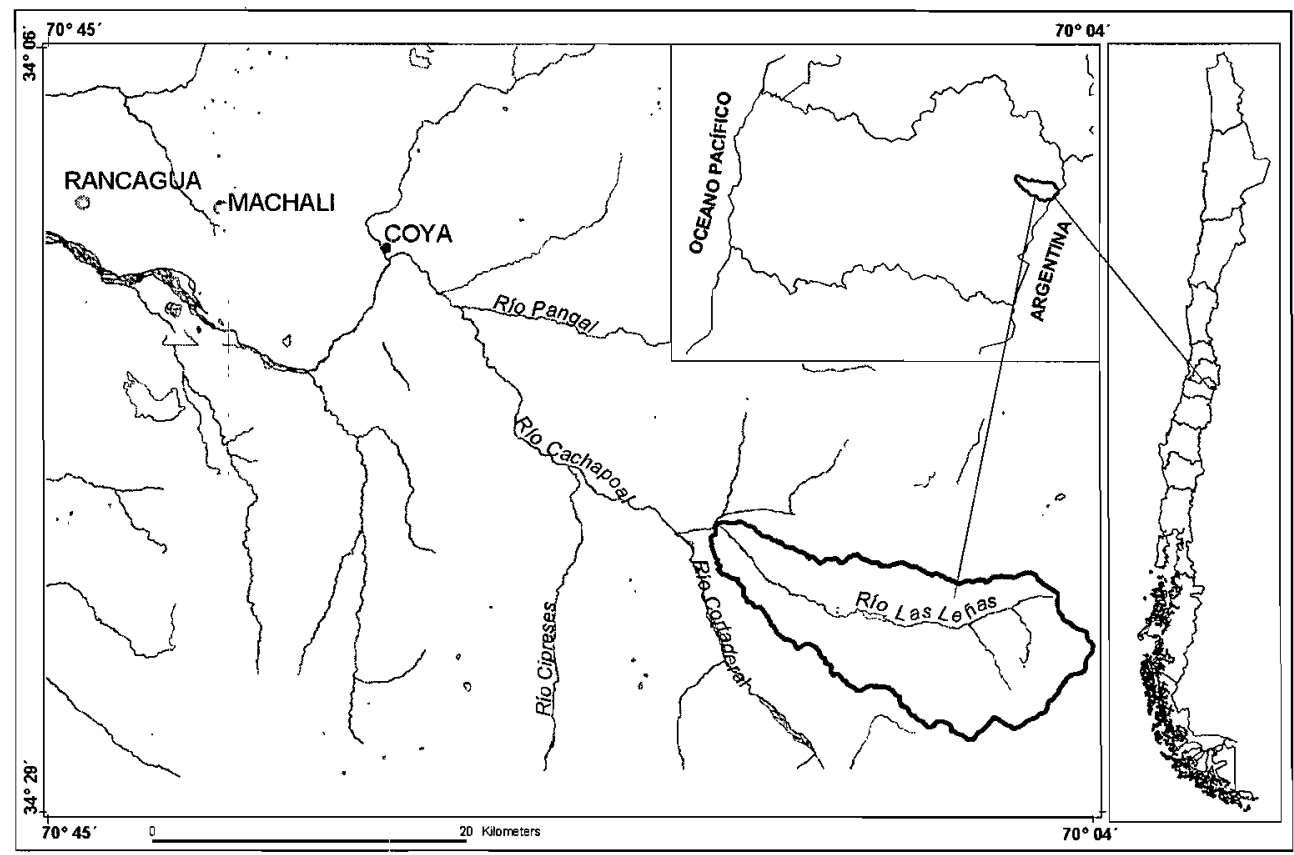

Fig. 1. Localización del área de estudio.

Fig. 1. Study area location. 
intercalaciones de lutitas fosilíferas (CORVALAN, 1959). Estas características están condensadas en VICENTE et al. (1973).

Separando las secciones media y alta, existe una falla vertical. A partir de ella, la sección alta corresponde a un complejo de rocas sedimentarias clásticas, con intercalaciones de potentes series de rocas volcánicas, efusivas y piroclásticas (CHARRIER, 1983).

\section{Procedimientos}

Para clasificar las vertientes, se usó la clasifícación de ARAYA - VERGARA (1985), en el contexto de su aplicación para otras áreas de montaña (ARAYA - VERGARA 1988 y 1996). Se consideraron las siguientes categorías de formas:

Sistemas de vertientes. La determinación de la morfotectónica y la estructura en la cuenca y su incidencia fue considerada para interpretar el modelado de las vertientes, de acuerdo con las características de fallamiento, estratificación y plegamiento estudiadas por CORVALAN (1959), KLOHN (1960), VICENTE et al. (1973), CHARRIER (1983) y CHARRIER et al. (1997). Se asume que estas características estructurales han sido favorables a la activación de movimientos en masa de la categoría de los flujos, como se ha observado en ambientes de montaña por MORALES (1988), WILLUMSEN (1989), MESINA et al. (2001), CASTRO et al. (2002), MESINA (2003), SOTO \& CASTRO (2003), CASTRO et al (2003), SOTO et al (2004).

Formas asociadas a los taludes La clasificación de sistemas de vertientes de ARAYA - VERGARA (1985) incluye en algunos de sus taxones el concepto de talud asociado a las caras libres. Sin embargo, para el caso de los depósitos basales del valle principal del río Las Leñas, estos han sido individualizados también en relación con la acción de disección y retrabajo paraglacial, si se usa los términos de BALLANTYNE (2002).
Relaciones fluvio-periglaciales Ellas fueron establecidas observando el contacto entre la base de los conos de talud y el canal fluvial principal, en términos de las formas debidas a remoción fluvial y los tipos de canal, como indicadores de transferencia de masa en la generación de aluviones.

La representación planimétrica de los sistemas se logró con fotointerpretación (vuelo GEOTEC 1996, escala 1:50.000) y mapeamiento de terreno. Para la carta geomorfológico se utilizó la leyenda de sistemas de vertientes de ARAYA-VERGARA (1985), y del CENTRE NATIONAL DE LA RECHERCHE SCIENTIFIQUE (1972), adaptado según PEÑA et al. (1997).

\section{RESULTADOS}

\section{Sistemas de vertientes y formas deposicionales asociadas (Figs. 2 a 10)}

\section{Sistemas de vertientes de excavación.}

Estas vertientes corresponden a los sistemas modelados como circos, con pendientes muy escarpadas a las que se asocian importantes depósitos basales (Fig. 2). Ellas se localiza en los sectores de cabecera de cuenca, siendo muy expresivas en el flancos de valle sur, donde exponen estructuras estratificadas y plegadas. Se presentan como una sucesión de circos coalescentes en los que el intenso trabajo de disección y excavación glacial y nival ha modelado cuencas con cabeceras de caras libres rugosas. A éstas están asociados taludes de avalancha.

Las formas deposicionales correlativas corresponden principalmente a amplios y altos conos que conforman taludes de avalanchas asociados a los circos del flanco norte, los que aportan detritos directamente al fondo de valle. Sin embargo en los sistemas de vertientes de excavación del flanco sur, no se aprecia taludes y conos tan sobresalientes y en su lugar se han desarrollado prominentes sistemas de glaciares rocosos. 


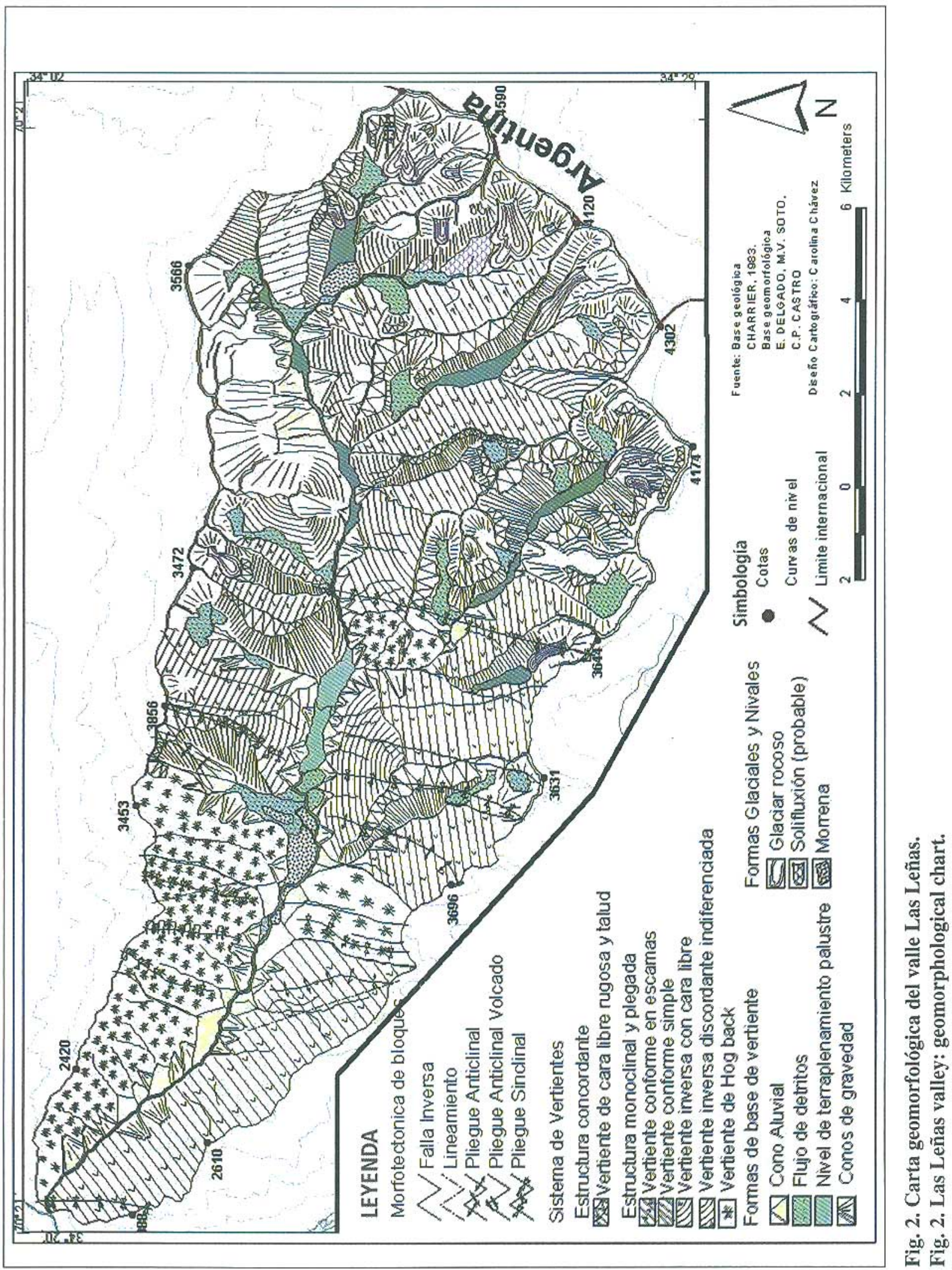


Los glaciares rocosos son formas muy puntuales en el área de estudio (Fig. 2), pero que constituyen un importante indicador de la acción de procesos transicionales glaciales y periglaciales, tal como SOTO et al. (2002) observaron en los altos Andes de la cuenca del río Limarí.

\section{Sistemas de vertientes en estructura monoclinal y plegada.}

Estos corresponden a los sistemas de vertientes en los que la influencia estructural, manifestada en afloramientos rocosos sobresalientes, constituye el aspecto morfogenético más relevante. En la clasificación de ARAYA VERGARA (1985) se pone el aporte de sedimentos en función del estilo morfoestructural en caras libres y la condición geodinámica. El rasgo estructural predominante de las vertientes de Las Leñas se asocia a un estilo de plegamiento y de fallas, siendo posible distinguir los siguientes sistemas de vertientes:

- Vertientes inversas Son sistemas que exponen en sentido contrario al buzamiento de los estratos, generando vertientes rugosas con peldaños y depósitos basales de talud. El aspecto general de estas vertientes es de caras libres con amplia exposición, marcada rugosidad y fuerte pendiente. Este tipo de sistema se ha desarrollado prácticamente en todo el valle. Se asocian a estas vertientes continuos taludes de gravedad, incididos por corredores de avalancha provenientes de las caras libres. Se presentan desprovistos de vegetación en la parte alta de la cuenca. Son los conos más grandes de todo el valle.

- Vertientes conformes Son sistemas que corresponden al reverso de las vertientes inversas y presentan una rugosidad relativa menor (Fig. 3), porque la vertiente se desarrolla en la misma direc- ción que los estratos rocosos, constituyendo vertientes consecuentes. Por esta razón presentan menor disección relativa. Aparecen dos tipos de vertientes, conformes simples y con escamas. Las primeras son más lisas. Las segundas contienen espolones rocosos y micro relieves con un patrón longitudinal (en el sentido de la pendiente); por su rugosidad mayor, se asume que son mejores suministradoras de materiales a las bases de vertiente.

Los depósitos asociados corresponden a expresivos taludes de gravedad, muy altos y continuos, especialmente aquellos ligados a los sistemas conformes con escamas, en tanto los de las vertientes conformes simples son sólo más bajos; en ambos casos se encuentran desprovistos de vegetación. En la carta geomorfológica (Fig. 2) sólo se han representado los conos de mayor tamaño, de tal manera que las formas de talud deben entenderse incluidas bajo el título sistema de vertiente, que no especifíca si hay taludes o no.

\section{Probables depósitos de solifluxión}

Este tipo de formas se desarrolla en vertientes conformes de estructuras plegadas en rocas sedimentarias continentales, en un paisaje local con menor rugosidad relativa. Se trata de formas localizadas en la sección alta de la cuenca, sólo en las vertientes de exposición SW. Se caracterizan por conformar conjuntos de lóbulos en las partes medias y basales de la vertiente (Fig. 2). Su ubicación coincide con una menor presencia de taludes, precisamente donde éstos están ausentes.

Esta categoría de depósito es poco representativa en el valle, pero se ha considerado como elemento indicativo de la dinámica de las vertientes de ambiente periglacial. Sin embargo, falta una descripción detallada de los depósitos para determinar con certeza su origen. 


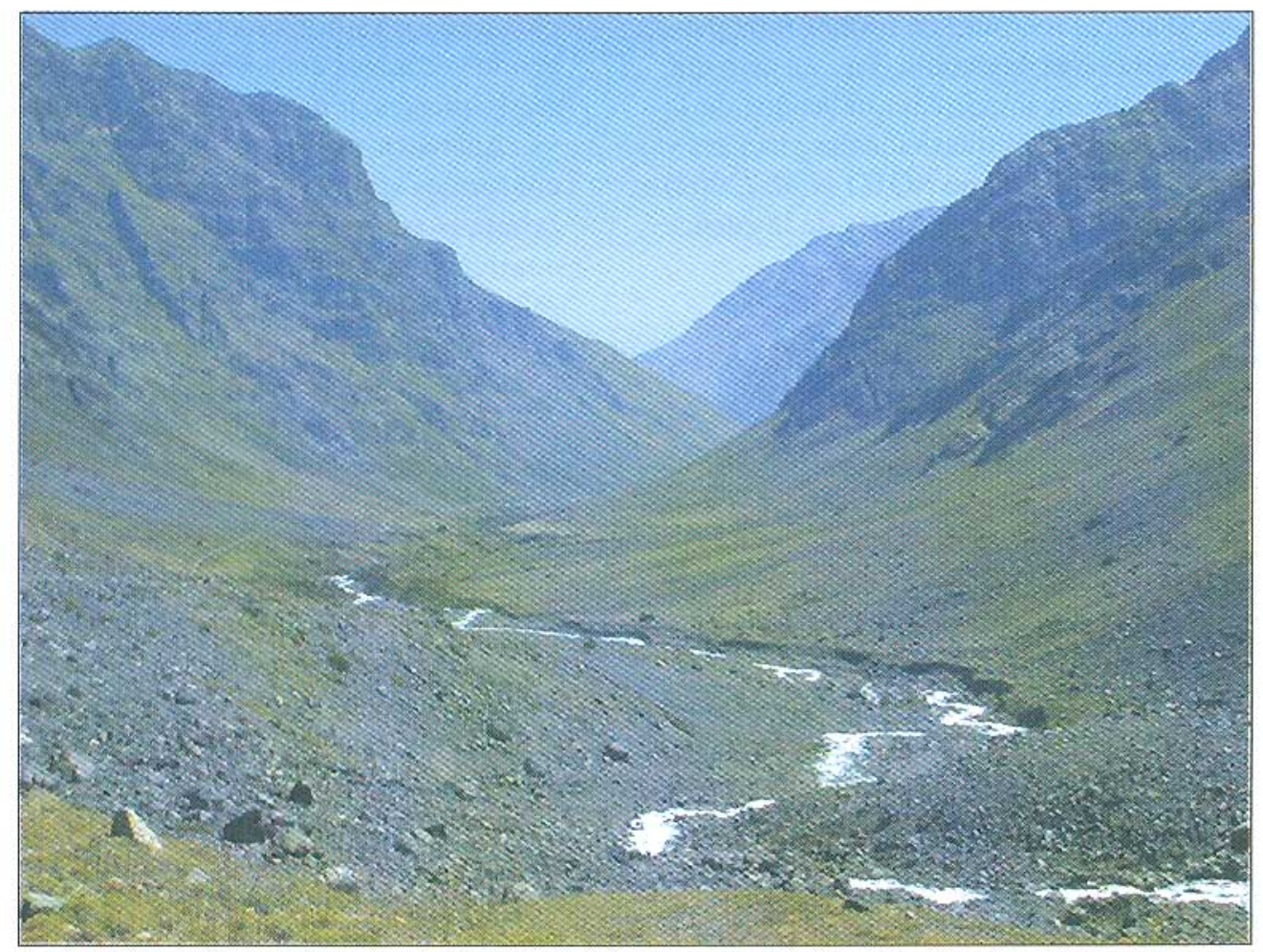

Fig. 3. Vertientes en el sector bajo. Flanco norte de valle (derecha): vertientes hogback. Flanco sur de valle: en estructuras plegadas, vertientes conformes con escamas. Los taludes tienen concavidad basal muy marcada y cobertura de hierbas bajas. La disección por flujos de detritos se evidencia en los depósitos de ambas vertientes. La relación entre actividad fluvial y taludes se expresa por la adaptación del talweg a la partes distales de los taludes y por la disección de los mismos.

Fig. 3. Slopes in the low sector. Northern valley side (right): hogback slopes. Southern valley side: on folded structures, conformable slope with fish scales. The talus has a very noticeable basal concavity and cover of low grass. The dissection associated to debris flows is exposed in the deposits of both slopes. The relationship between fluvial activity and talus is expressed by by the adlaptation of the talweg to talus distal part and its dissection.

Vertientes discordantes. Se trata de formas elaboradas en disposición transversal al buzamiento de los estratos en el monoclinal. Las vertientes discordantes del área de estudio presentan un aspecto general que las hace homólogas en forma y dinámica a las vertientes inversas, inclusive con rasgos más nítidos de exposición del monoclinal que en las inversas propiamente tales (Fig. 4). Este rasgo incide directamente en conos de grave- dad y taludes muy expresivos en altura, conformado taludes amplios y continuos, sobre todo en la parte media de la cuenca. donde estos sistemas de vertientes exponen al eje del valle principal.

El conjunto de vertientes asociadas a la estructura monoclinal presenta un arreglo característico, en que las vertientes inversas predominan en exposición oeste y las conformes, en exposición este; los flancos 
discordantes del monoclinal enfrentan al eje del valle principal. La relación inversa - conforme - discordante es ampliamente representativa en Las Leñas, asociada a las diferentes estructuras plegadas existentes.

- Vertientes de hogback. Corresponden a vertientes muy abruptas en que el buzamiento de los estratos es superior a los $60^{\circ}$, constituyendo una situación favorable para el aporte de detritos, en función de la exposición de los estratos rocosos a la acción de la meteorización. Consecuente con el tipo de rocas y los procesos tectónicos que las han afectado, el modelado ha estado marcado por el desarrollo de sistemas de vertientes en que el fuerte plegamiento configura estratos de orientación más bien vertical. Ésta es favora- ble para un aporte de detritos importante, observado en los expresivos depósitos correlativos (Fig. 5).

Consecuentemente los depósitos asociados constituyen extensos y altos conos coalescentes conformando prominentes taludes. Tales sistemas depositacionales sin embargo se presentan en diferentes grados de estabilización, de tal manera que en la parte baja de la cuenca se presentan bastante estabilizados por vegetación de matorral esclerófilo abierto. A pesar de esta estabilización relativa, también hay una fuerte condición de incisión de los taludes por flujos de avalanchas de carácter estacional, evidenciando así una marcada acción paraglacial en los depósitos de base de vertiente.

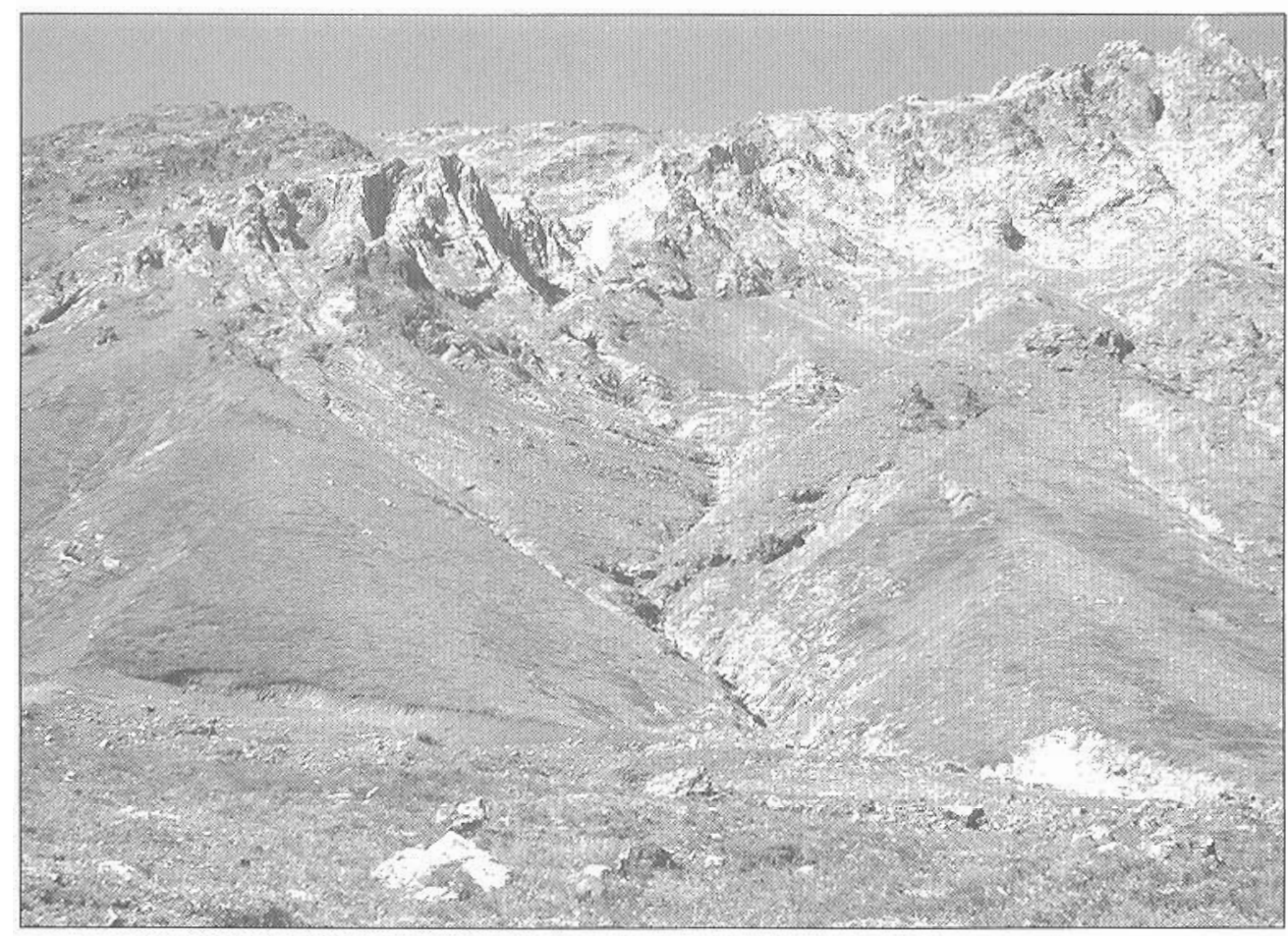

Fig. 4. Sector medio del valle Las Leñas. Vertientes discordantes, exponiendo la estructura monoclinal en estratos de rocas sedimentarias marinas calcáreas fuertemente plegadas. Los depósitos de base se encuentran en un buen nivel de estabilización por la vegetación.

Fig. 4. Middle sector. Discordant slopes showing monoclinal structures in beds of sedimentary marine rocks strongly folded are exposed. The basal deposits are in a good level of stabilization by the vegetation. 
Formas depositacionales más antiguas de fondo de valle.

Estas formas ya han sido descritas como morrenas (VARELA, 1986). Aquí sólo se precisará su relación aloestratigráfica con formas atribuidas al dominio periglacial. La presencia de depósitos morrénicos constituyen la barrera de represamiento natural de una laguna en la parte central de la cuenca, siendo posible identificar cordones bien conservados, pero escasos. Además, se observa remanentes morrénicos de orientación transversal al valle principal, sobre los que hay depósitos de avalanchas más recientes. Así, las formas descritas a continuación se consideran temporalmente post-glaciales.

\section{Taludes}

Éstos corresponden a las formas depositacionales más características del paisaje. Están formados por conos coalescentes que pueden ser tanto de gravedad como de avalancha. Se trata de cinturones continuos y territorialmente extensos. Ellos presentan diferencias de acuerdo con su rango de altitud en la cuenca.

En la sección baja (2.150-2.150 m.sn.m.) los taludes correlativos a vertientes conformes y de hogback (Fig. 6) presentan un perfil cóncavo y una pendiente menor con respecto a los de las partes altas. Se caracterizan principalmente por el grado de estabilidad asocia-

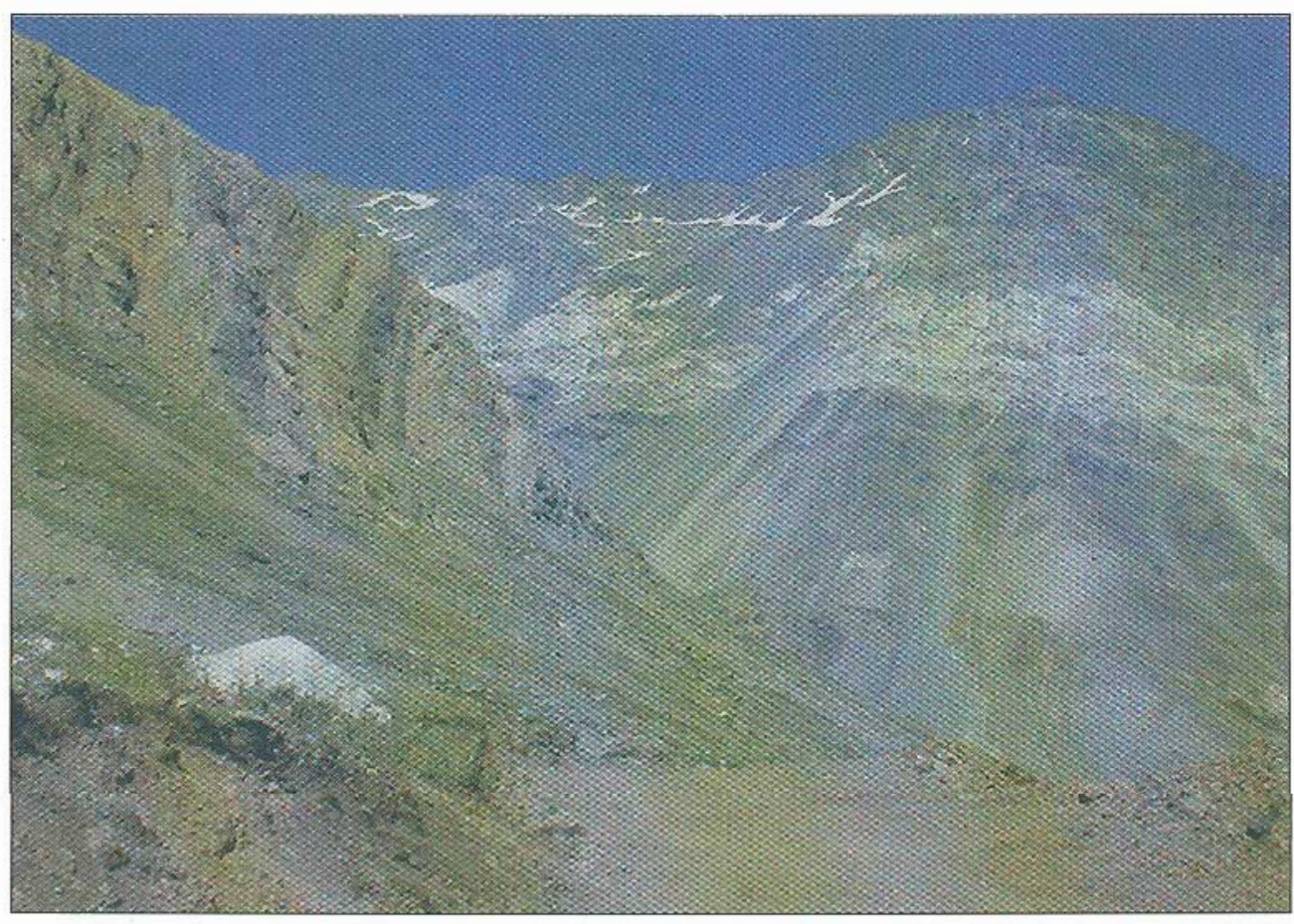

Fig. 5. Sector medio. Vertientes hogback, exponiendo estratos sedimentarios marinos, con buzamiento casi vertical. En segundo plano, sistemas de vertientes en posición conforme, con elevados taludes.

Fig. 5. Middle sector. Hogback slopes exposing marine sedimentary layers, with almost vertical dip. At background, conformable slopes systems are observed coexisting with high gravitational cones. 
do a una cobertura de matorral esclerófilo abierto que varía, según la altura del valle, a una cubierta de hierbas bajas. Los taludes son incididos marcadamente por la acción paraglacial.

En la sección media del valle (1.150-2.400 m.s.n.m), es posible encontrar potentes depósitos de gravedad y de avalanchas, los que VARELA (1986) determinó como post-glaciales; están totalmente desprovistos de vegetación (Fig. 7). En este lugar los sistemas de vertientes discordantes muestran estratos rocosos muy potentes y rugosos, en un sector que presenta la mayor densidad de lineamientos y fracturas (Fig. 2), en estruc- turas plegadas. La acción paraglacial es menos evidente en éstos. Sin embrago, aguas arriba, entre $\operatorname{los} 2.200$ y $\operatorname{los} 2.400-3.300$ m.s.n.m., los taludes característicos son muy elevados y escarpados, con perfil rectilíneo y estabilizados por una cubierta vegetal homogénea de hierbas bajas (Fig. 8) y fuertemente incididos por la acción paraglacial, encontrándose en este sector la incisión de taludes más acentuada de todo el valle (Fig.9)

Es a partir de los 2.400 m.s.n.m. donde el paisaje se torna cada vez más periglacial, con vertientes muy escarpadas y depósitos gravitacionales sin vegetación. En esta parte

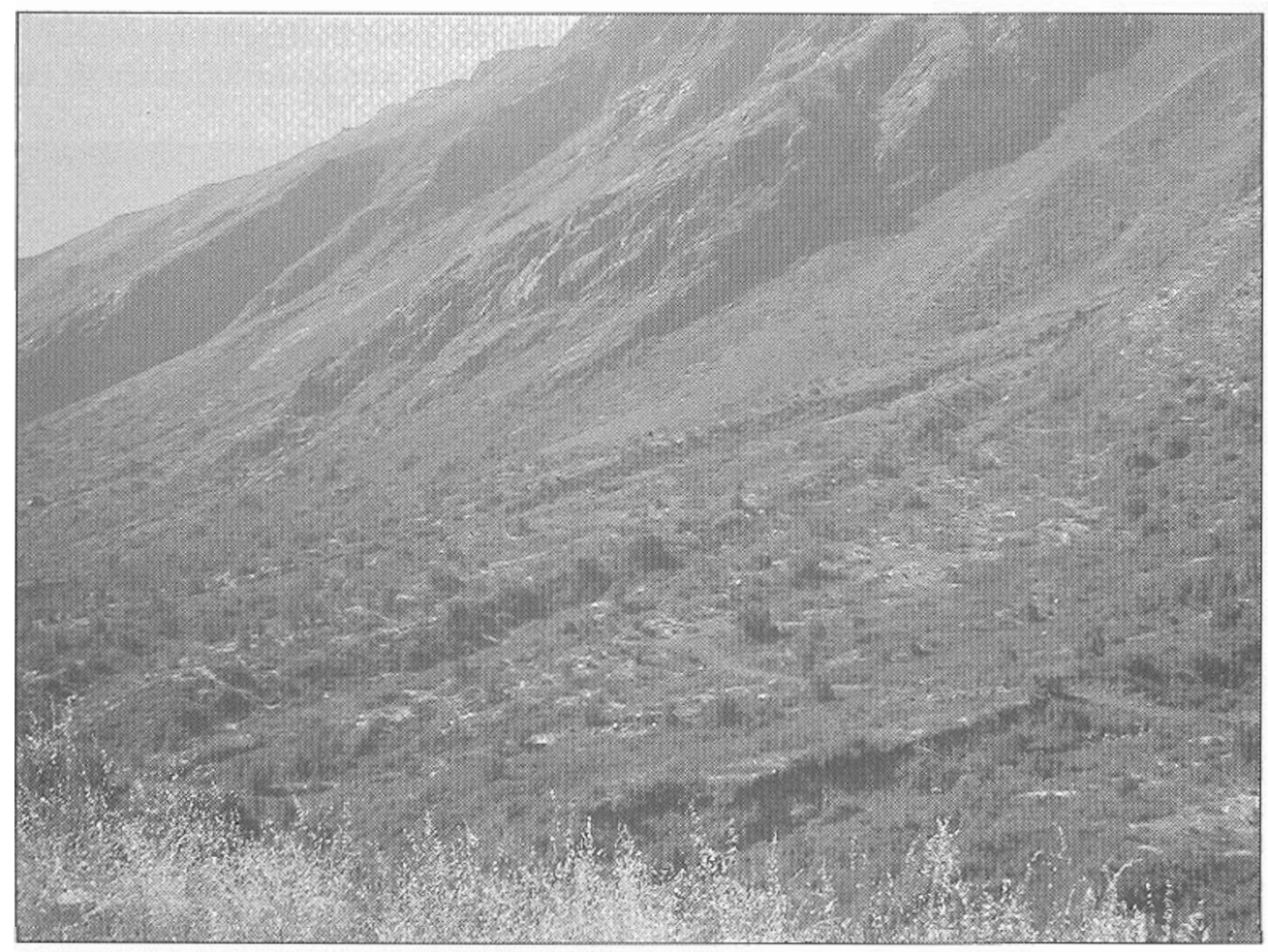

Fig. 6. Sector bajo del valle. Vertiente hogback. Los conos forman taludes de perfiles muy cóncavos. La condición ambiental de menor altitud es demostrada por la cobertura vegetacional más desarrollada en los depósitos basales estabilizados, pero disectados por procesos de avalancha.

Fig. 6. Low sector of the valley. Hogback slopes. The cones conform a talus with very concave profile. The environmental position of lower altitude is expresed by the more developed plant cover than upstream, on the talus, which is dissected by avalanche tracts. 
del valle se localizan los circos, los glaciares rocosos y cuerpos remanentes de hielo en los pequeños valles más altos (Fig. 10).

\section{Formas depositacionales de vertiente y su} relación con las formas fluviales

\section{Relación entre taludes y canales fluviales}

El fondo del valle está ocupado por las partes distales de los conos de talud (Fig. 2), cuya coalescencia lateral y convergencia frontal condicionan el drenaje del río. En éste, el canal de lecho mayor es esencialmente meándrico (Fig. 3). Sus escarpas limitantes indican que puede haber erosión fluvial en la base de los conos, pero que ella es leve, puesto que las escarpas sólo se restringen a delimitar el meandro. De este modo, la presencia de los conos calibra fuertemente el escurrimiento fluvial. Este comportamiento, importante en las relaciones fluvio-periglaciales, es común en cuencas altas de la región (ARAYAVERGARA, Dep. de Geografía, Universidad de Chile, comunicación personal).

\section{DISCUSION}

La dinámica de los sistemas de vertientes, su relación genética con los depósitos basales correlativos y el retrabajo de estos, son sistematizadas a continuación:

\section{Dinámica de los sistemas de vertientes.}

La presencia de altos estratos aflorantes en la estructura monoclinal constituye condiciones favorables para la detritificación de las

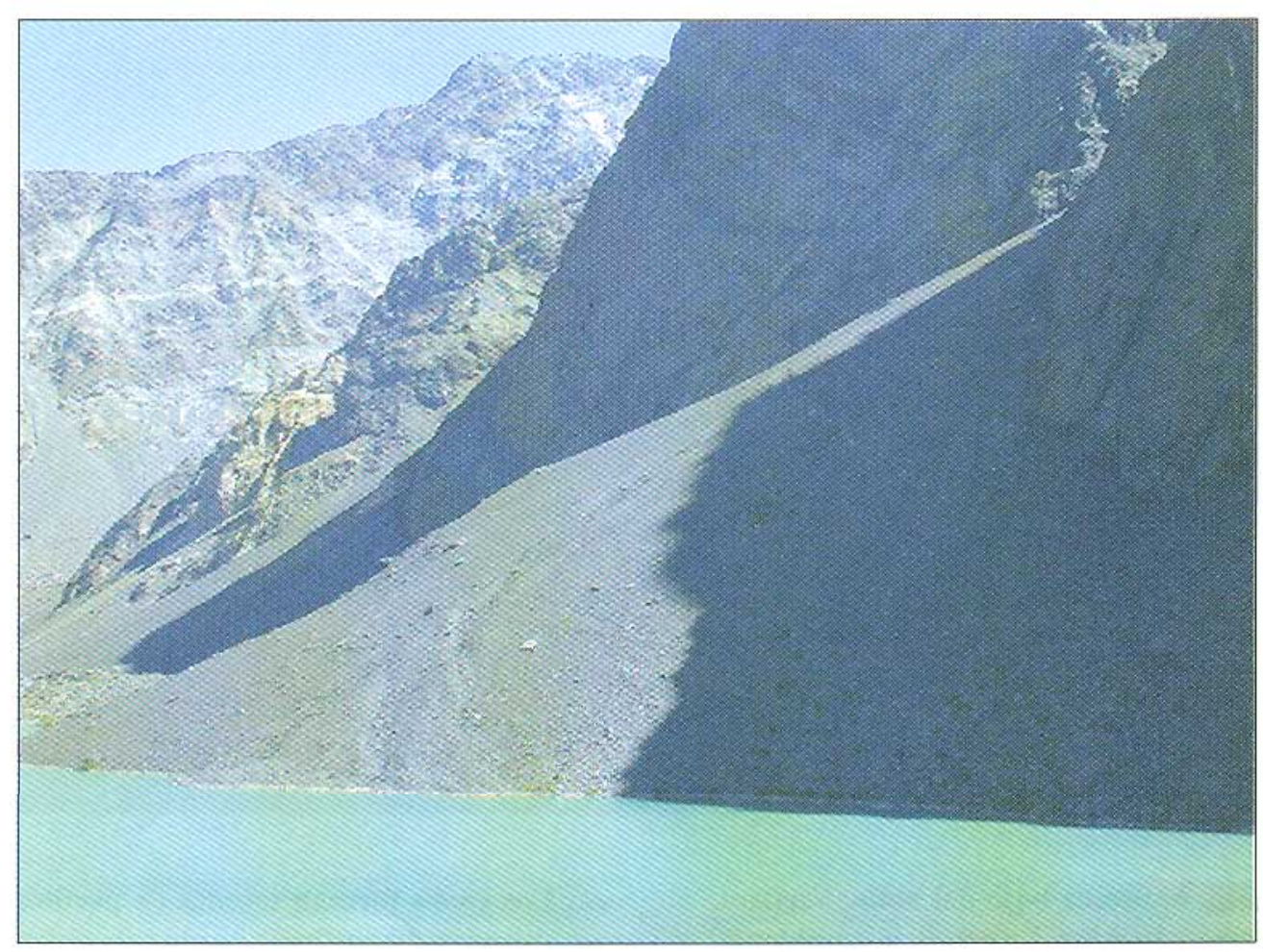

Fig 7. Sector medio. Vertientes discordante en estructura plegada. En este sector se presentan grandes cono de gravedad activos, totalmente desprovistos de vegetación.

Fig 7. Middle sector. Discordant slopes in folded structure. A high level of gravitational processes is active in the area. This condition is expressed by the lack of vegetation in cones. 
rocas, que permite el desarrollo de importantes depósitos basales, en que el aporte detrítico relativo es mayor donde los estratos rocosos están en condición de exposición a la acción de la geodinámica externa, como ocurre generalizadamente en las vertientes inversas y discordantes. Esta relación se confirma a través de la observación de los depósitos correlativos, puesto que los sistemas de vertientes inversas y discordantes presentan en su base depósitos muy elevados, activos y con marcadas evidencias de la acción paraglacial de flujos de avalanchas. aquellas denominadas en este trabajo como sistemas conformes, son las que presentan las mayores frecuencias de procesos de deslizamientos de rocas, en los Rocky Mountain de Canadá. HAUSER (1993) señala al respecto que las secuencias volcanoclásticas estratificadas de la Cordillera de los Andes presentan condiciones propicias para éste tipo de fenómenos, siendo un ejemplo de ello el deslizamiento de rocas de la Formación Río Damas que ocasionó el gran flujo de detritos de Río Colorado en $1987\left(33^{\circ} 30^{\prime} \mathrm{S}-70^{\circ} 00^{\prime} \mathrm{W}\right)$.

Para la cuenca del río Mapocho ( $33^{\circ} 30^{\prime} \mathrm{S} /$ $71^{\circ} 30^{\prime}$ W), ARAYA - VERGARA (1985)

Sin embargo, CRUDEN \& HU (1993) señalan que estos tipos de vertientes y sobre todo

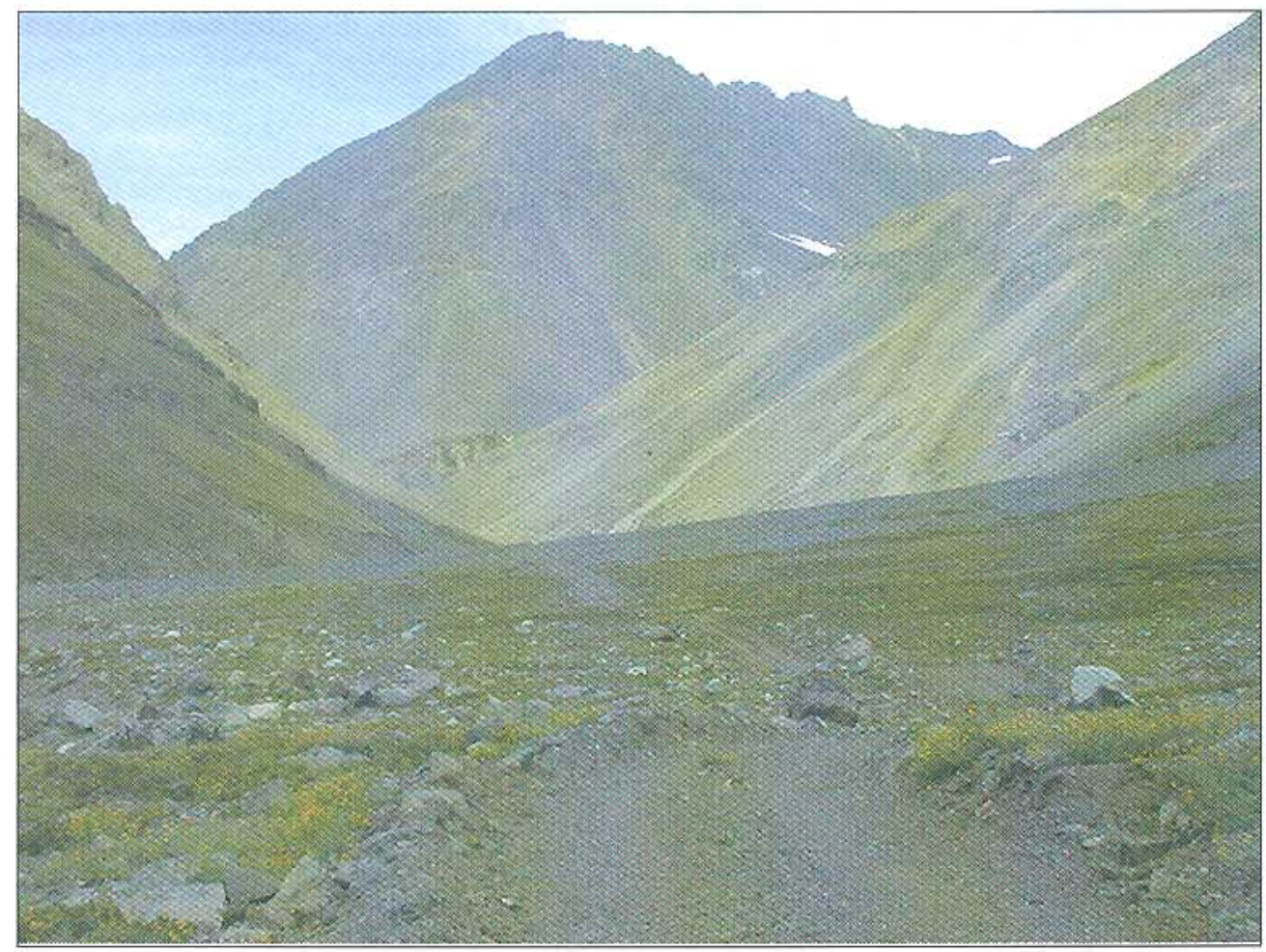

Fig. 8. Vista hacia la sección alta del valle, conformado por vertientes modeladas en estructuras plegadas de rocas sedimentarias continentales. Los taludes muy elevados y escarpados tienen perfiles rectilíneos. Los depósitos basales están estabilizados por la vegetación. Hay evidencia de la disección de los conos por los flujos de avalancha.

Fig. 8. View toward the high section of the river valley. The slopes were formed in continental sedimentary folded rock layers with a very high and scarped talus. The basal deposits are stabilized by the vegetation. Cones are dissected by avalanche flows. 


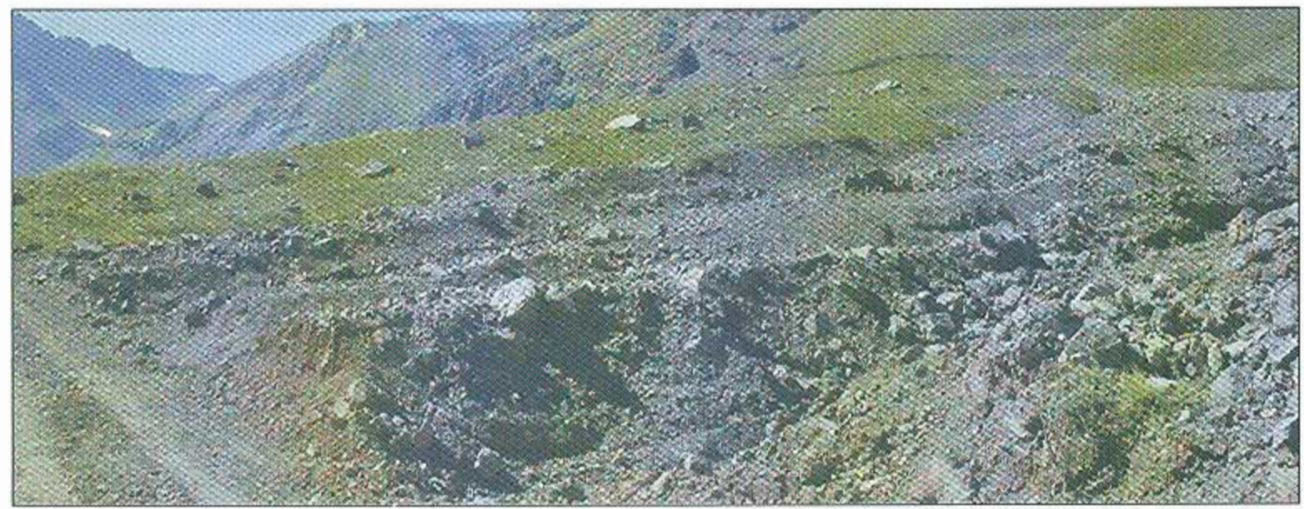

Fig. 9. Formas depositacionales de vertiente estabilizadas por la vegetación, disectadas y retrabajadas por flujos de avalancha.

Fig. 9. Slope depositional features stabilized by the vegetation, dissected and reworked by avalanche.

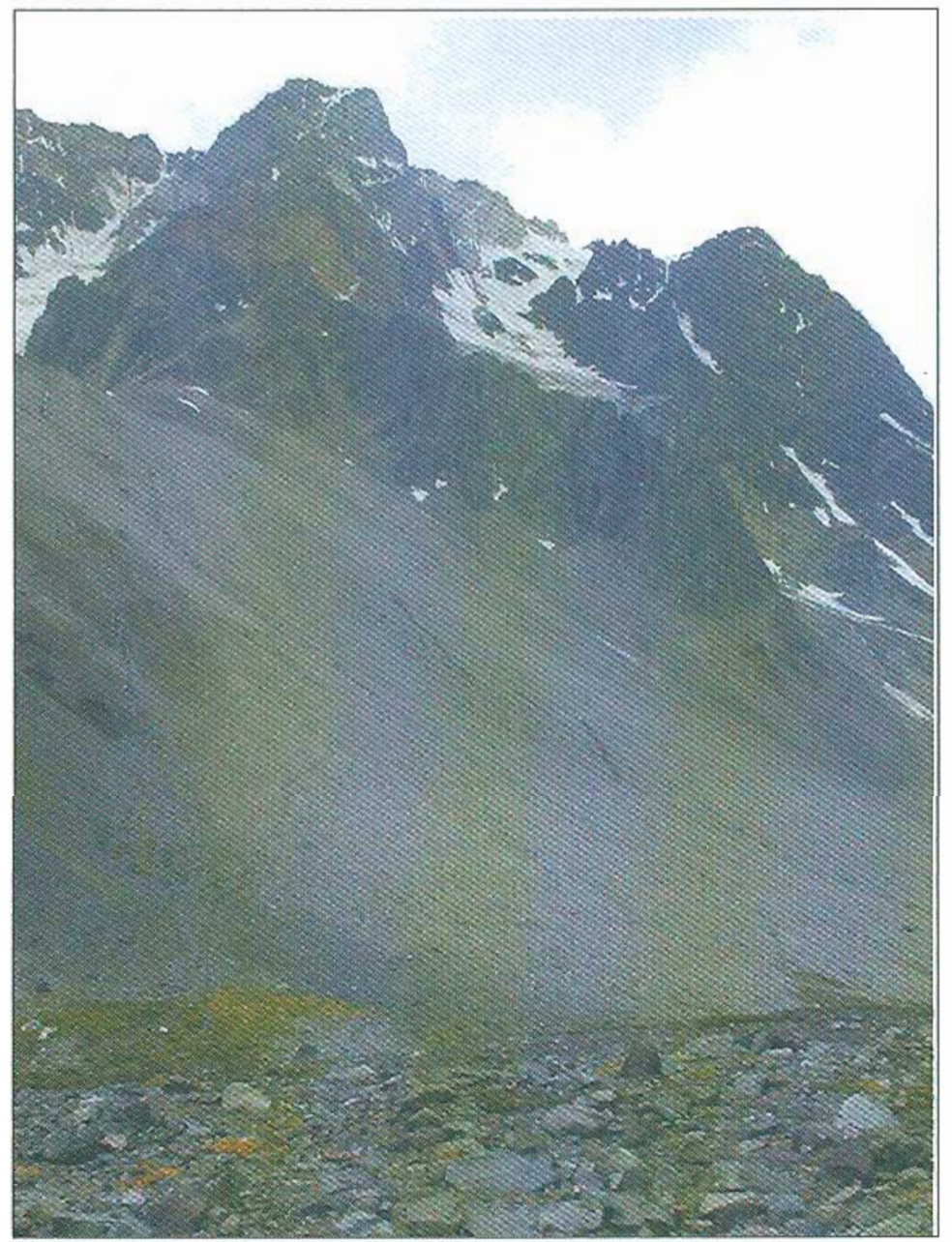

Fig. 10. Vista hacia las altas cumbres del flanco de valle. Paisaje asociado a la acción periglacial, con vertientes de fuerte pendiente y taludes móviles, disectados por flujos coluviales.

Fig. 10. View toward de valley flank. A landscape associated to the periglacial system is appreciated. The slopes are strongly steep and shows movable talus affected by debris flow dissection. 
observó que las formas morrénicas de valles altos asociados a circos del Cuaternario y al dominio nival y periglacial en la actualidad, inciden en la potencialidad de las vertientes para proporcionar detritos por gelifracción. Éstos son importantes, porque las paredes de los circos son sectores de avalancha. Esta relación se aplica para los circos altos de Las Leñas modelados en rocas sedimentarias estratificadas y plegadas, favorables al suministro de detritos. Los elevados y anchos conos de gravedad correlativos a los circos del flanco norte del valle dan cuenta de esta relación.

\section{Depósitos basales y geodinámica moderna}

Los depósitos basales correlativos a los sistemas de vertientes monoclinales no presentan una gran diferencia y variedad de formas, sino del estado relativo de estabilización de los taludes. El grado de similitud entre los depósitos de base de vertientes de la sección baja y alta del valle, no puede ser explicado solamente en función a la litología y edad de las formaciones rocosas, tectonismo, estilo, exposición y grado de plegamiento de los estratos. El fenómeno es más complejo. Longitudinalmente a la dirección del valle se suceden taludes de distinto grado de evolución. Unos están relativamente estabilizados, aunque disectados por corredores de avalanchas de detritos. Otros son activos, esencialmente como formas de gravedad, aunque también disectados por corredores de avalancha de detritos.

Los procesos de avalancha como agentes dinámicos actuales de las vertientes, que inciden profundas cárcavas, retrabajan y disectan depósitos preexistentes, han sido documentados por BLIKRA \& NEMEC (1998), CURRY (1999), BALLANTYNE (2002) en ambientes periglaciales del hemisferio norte, y también corresponden a las formas más características en el valle de Las Leñas. Tales flujos de características paraglaciares inciden prácticamente todos los depósitos, independientemente del tipo de vertiente al cual se asocian.
Por su parte, los sistemas gravitacionales, aunque dependen de las condiciones geomorfológicas locales, son muy sensibles a los cambios climáticos regionales (BLIKRA \& NEMEC, 1998). Las intensas y concentradas precipitaciones acontecidas durante el invierno del 2002, ocasionaron el retrabajo y reactivación de las formas depositacionales, comprobándose una gran capacidad de arrastre de carga sólida, generando notables incisiones y acumulaciones correlativas de material fresco asociadas a flujos de avalanchas (CASTRO et al. 2002, SOTO \& CASTRO 2003, CASTRO et al 2003, SOTO et al 2004).

Conjuntamente, la dinámica de los flujos de avalancha es sistemáticamente más recurrente en los sistemas de vertiente y talud a medida que se asciende en el piso altitudinal hacia condiciones periglaciales más intensas, presentando consecuentemente una mayor densidad, nivel de disección y capacidad de carga asociada. Para interpretar esto pueden ser consideradas la forma del perfil transversal y grado de confinamiento del valle. Así, las condiciones de estabilidad relativa de los depósitos basales, pueden ser explicadas considerando el clima local. Análisis de GARREAU (2003) indican que existe una menor amplitud del ciclo diario de las temperaturas, lo está asociado al confinamiento y estrechez del valle, que reducen la pérdida radiativa infrarroja durante la noche, induciendo a una tendencia de menor enfriamiento relativo.

Al analizar la condición dinámica de los sistemas de vertientes a la luz de sus implicanciones en estados de amenaza y riesgos naturales, asociados a procesos de remoción en masa, por gravedad, flujos y deslizamientos de rocas, CASTRO et al (2003) encontraron que el ambiente morfoclimático del piso periglacial caracteriza al valle por su alto nivel de amenaza ligado a la dinámica de las vertientes y depósitos correlativos. HAUSER (1993) al relatar los procesos de remoción en masa en Chile, señala a la sismicidad como un 
agente morfogénetico fundamental, sobre todo en los ambientes de cordillera tectonizada. En las Leñas esta condición ha sido confirmada por COMTE (2003), quien ha registrado durante 2 años la sismicidad superficial de la zona.

\section{CONCLUSIONES}

Los sistemas de vertientes del valle del Cachapoal corresponden principalmente a tipos asociados al arreglo y exposición de los estratos rocosos en una estructura monoclinal. La condición de exposición de estas estructuras implica una alta potencialidad de detritificación y difusión de materia desde las vertientes.

Los procesos de denudación, erosión y disección de los depósitos de base de vertientes corresponden a flujos de detritos torrenciales de marcada estacionalidad. Estos flujos retrabajan y activan depósitos gravitacionales, correlativos a todos los sistemas de vertientes.

El patrón reconocido de acción de los flujos de avalanchas en los depósitos, es el aumento sistemático de la densidad y profundidad de las cárcavas y surcos de excavación en función al ascenso en el piso altitudinal periglacial de altura.

Consecuentemente, los depósitos de base de vertiente y la acción estacional de los flujos de avalancha, constituyen las formas más representativas de la geodinámica externa actual en el valle estudiado, cuyo grado de representatividad para Chile Central puede establecerse después de futuros estudios comparados.

Para expresar mejor estos rasgos en función de su importancia para la detección de zonas de peligros y riesgos, es necesaria una cartografía detallada. En los productos de investigación actual (ver referencias) se está empezando a poner énfasis en la indicación de zonas de run-out o extensión distal de los flujos, lo que puede ser mapeado (ARAYAVERGARA, comunicación personal).

\section{AGRADECIMIENTOS}

Las autoras agradecen a los profesores María Mardones de la Universidad de Concepción, Roland Paskoff de la Universidad de Lyon y al geólogo Arturo Hauser la revisión crítica del manuscrito, de la misma manera que al Profesor José Araya-Vergara, por su valiosa contribución en el desarrollo de la versión final. Se agradece también al Sr. Sergio Cuevas y su familia, por la colaboración y apoyo logístico en las campañas de terreno al Valle de Las Leñas.

\section{REFERENCIAS}

ARAYA-VERGARA, J.F., 1985. Análisis de la carta geomorfológica de la cuenca del Mapocho. Inform. Geogr. Chile, 32: 31-44.

ARAYA-VERGARA, J.F., 1988. Toward a classification of slope systems. $26^{\text {tha }}$ Congress Inter. Geogr. Union. Abstract. Sydney, Vol.1. 1:19 A2.

ARAYA-VERGARA, J.F., 1996. Primeras experiencias con una clasificación dinámica de vertientes de montaña. En: The United Nations University (Ed.), 1er Taller Internacional de Geoecología de Montaña y Desarrollo Sustentable de los Andes del Sur. The United Nations University, Viña del Mar, pp. 389-399.

BALLANTYNE, C.K \& D.I. BENN, 1994. Paraglacial slope adjustement and resedimentation following recent glacier retreat, Faberstolsdalen, Norway. Artic and Alpine Research, 26: 255-269.

BALLANTYNE, C.K., 2002. Paraglacial geomorphology. Quat. Sci. R., 21:1935-2017.

BENN, D.I. \& D. EVANS, 1998. Glaciers and Glaciation. Arnold Editors, London.

BLIKRA, L.H. \& W. NEMEC, 1998. Postglacial colluvium in Western Norway: depositional processes, facies and paleoclimatic record. Sedimentology, 45: 909-959. 
BLOOM, A., 1978. Geomorphology, a Systematic Analysis of Cenozoic Landforms. Prentice Hall, Englewood Cliffs, N.J.

CASTRO, C.P., M.V.SOTO, G. IGOR \& E. DELGADO, 2002. Análisis comparativo de los riesgos geomorfológicos de alta montaña. Valle del río Limarí y del río Cachapoal. En: Anales de la Sociedad Chilena de Ciencias Geográficas, s/n: 3-12.

CASTRO, C.P., M.V. SOTO \& C. CHAVEZ, 2003. Aporte moderno de masa y su implicancia en la definición de niveles de riesgo natural. Tiempo y Espacio, 13:185199.

\section{CENTRE NACIONAL DE LA} RECHERCHE SCIENTIFIQUE (ED)., 1972. Mémoire et documents. Cartographie Géomorphologique, travaux de la R.C.P. 77. Service de Documentation et de Cartographie Géographiques, Nouvelle Série, Vol. 12, Paris.

CHARRIER, R., 1983. Carta Geológica de Chile. Hoja El Teniente. Servicio Nacional de Geología y Minería, Inédito, Santiago.

CHARRIER, R., J. FLYNN, A. WYSS, F. ZAPATTA \& C. SWISHER, 1997. Antecedentes bio y cronoestratigráficos de la Formación Coya- Machalí-Abanico, entre los ríos Maipo y Teno ( $33^{\circ} 55^{\prime}$ y $35^{\circ} 10^{\prime}$ L.S.) Cordillera Principal, Chile Central. En: Actas VIII Congreso Geológico Chileno., Vol. 1, Antofagasta, pp. 165-169.

COMTE, D., 2003. Determinación de niveles de riesgo en el corredor de comercio Las leñas, VI Región. Informe Final Proyecto DI TNAC 11-02/01. Universidad de Chile, Inédito, Santiago.

CORVALAN, J., 1959. El Titoniano del Río Las Leñas, Provincia de O'Higgins. Instituto de Investigaciones Geológicas, Boletín $\mathrm{N}^{\circ}$ 3, Santiago.

CRUDEN, D.M. \& X. Q. HU., 1993. Exhaustion and steady state models for predicting landslide hazard in the Canadian Rocky Mountains. Geomorphology, 8: 279285.

CURRY, A. M., 1999. Paraglacial modification of slope form. Earth Surface Processes and Landforms, 24:1213-1228.

DELGADO, E., 2004. Determinación de niveles de riesgo en el corredor de comercio Las leñas, VI Región. Informe Final Proyecto DI TNAC 11-02/01. Universidad de Chile, Inédito, Santiago.

EMBLETON, C. \& C. KING, 1975. Periglacial Geomorphology. Edward Arnold, London.

FRENCH, H., 1976. The periglacial environment. Longman, London.

GARREAU, R., 2003. Determinación de niveles de riesgo en el corredor de comercio Las leñas, VI Región. Informe Final Proyecto DI TNAC 11-02/01. Universidad de Chile, Inédito, Santiago.

HAUSER, A. 1993. Remociones en masa en Chile. Servicio Nacional de Geología y Minería, Chile,

Boletín $N^{\circ} 45$, Santiago.

KLOHN, C., 1960. Geología de la Cordillera de Los Andes de Chile Central. Provincias de Santiago, O'Higgins, Colchagua y Curicó. Instituto de Investigaciones Geológicas, Boletín $\mathrm{N}^{\circ} 8$, Santiago.

KOTARBA, A., 1984. Elevational diferentiation of slope geomorphic processes in the Polish Tatra Mountains. Studia Geomorphologica Carpatho - Balcanica, 18: 117-133.

KOTARBA, A., 1992. High-energy geomorphic events in the Polish Tatra Mountains. Geografiska Annaler, 74 A (2-3): 123-131.

MATTHEWS, J.A., R. SHAKESBY, L. MCEWEN, M. BERRISFORD, G. OWEN 
\& P. BEVAN, 1999. Alpine debris-flows in Leirdalen, Jotunheimen, Norway, with particular reference to distal fan, intermediatetype deposits, and flow types. Artic, Antartic, and Alpine Research, 31 (4): 421-435.

MORALES, B., 1988. Análisis morfoestructural y morfodinámico de las vertientes y de los talwegs afluentes del BioBío, su distribución espacial y sus eventuales alteraciones por la implementación de la Central Hidroeléctrica Pangue. Informe Final de Práctica Profesional para Optar al Título de Geógrafo. Universidad de Chile, inédito, Santiago,

MESINA, A., M.V.SOTO \& C.P. CASTRO, 2001. Clasificación de Niveles de Riesgo Natural a Partir de la Carta Geomorfológica en el Corredor de Comercio Doña Rosa, Región de Coquimbo. En: Universidad de Chile (Ed.), $8^{\circ}$ Encuentro de Geógrafos de América Latina. Publicación Digital, Santiago..

MESINA, A., 2003. Análisis del sistema físico natural en la detección de peligros naturales: definición de áreas de riesgo natural. Memoria para optar al Título de Geógrafo. Facultad de Arquitectura y Urbanismo, Universidad de Chile, inédito, Santiago.

NOGAMI, M., 1976. Altitude of the modern snowline and Pleistocene snowline in the Andes. Geogr. Rep. Tokio Metropol. Univ., 11: 71-86.

PEÑA. J.L., F. PELLICER CORELlaNo, J. CHUECA CÍA \& A. JULIÁN ANDRÉS, 1997. Leyendas para mapas geomorfológicos a escalas 1: 100.000/ 1: 200.000 y 1: 25.000/1: 50.000. En: Peña Monné, J.L. (Ed.), Cartografía geomorfológica básica y aplicada. Geoformas Ediciones, Logroño, pp. 127-143.

RAPP, A., 1960. Recent development of mountain slopes in Kärkevagge and surroundings, Northern Scandinavia. Geogr. Ann., 42: 65-200.
SOTO, M.V., (1991). Caracterizaçao morfosedimentológica do micro leque deltaico da Baia Esperança, Península Foldes, Ilha Rei Jorge, Shetland do Sul, Antártica. Tesis de Magister en Geociencias. Universidade Federal do Río Grande do Sul, inédito, Porto Alegre

SOTO, M.V. \& C.P. CASTRO, 2003. Dinámica de los sistemas de vertientes de alta montaña, cuenca del río Cachapoal, Chile. En: $10^{\circ}$ Congreso Geológico Chileno, Publicación Digital, Concepción.

SOTO, M.V., F. FERRANDO \& R: VIEIRA, 2002. Características geomorfológicas de un sistema de glaciares rocosos y de su cuenca de sustentación en Chile semiárido. Invest. Geogr. Chile, 36: 1-15.

Soto, M.V., C.P. CASTRo \& C. CHAVEZ, 2004. Caracterización geomorfológica del corredor de comercio Las Leñas, Valle del río Cachapoal, Andes de Chile Central. R. Geogr. Norte Grande, 31: 85-98.

VANDENBERGHE, J. \& MING-KO WOO, 2002. Modern and ancient periglacial river types. Progress in Physical Geography, 26 (4): 479-506.

VARELA, J., 1986. Estudio geológicogeomorfológico de los depósitos del relleno cuaternario del valle del río Las Leñas en el sector de Laguna del Yeso-Borbollones, VI Región. Departamento de Geología. Universidad de Chile, inédito, Santiago.

VICENTE, J.C., R. CRARRIER, J. DAVIDSON, A. MPODOZIS \& S. RIVANO, 1973. La orogénesis subhercínica: fase mayor de la evolución paleogeográfica y estructural de Los Andes argentino-chileno centrales. En: Actas del Quinto Congreso Geológico Argentino, Buenos Aires, Tomo 5, pp. 81-98.

WEISCHET, W., 1968. Zur Geomorphologie de Glatthang-Reliefs in der ariden 
Subtropenzone des Kleines Nordens von Chile. Z. Geomorph., N.F., 13 (1): 1-21.

WILLUMSEN, H., 1989. Caracterización y evaluación de formas y procesos morfológicos actuales en la cuenca del Estero Yerba
Loca. Informe Final de Práctrica Profesional para Optar al Título de Geográfo, Universidad de Chile, inédito, Santiago.

YOUNG, A., 1977. Slopes. Longman, London.

\section{Imagen de Investigaciones GEOGRÁFICAS}

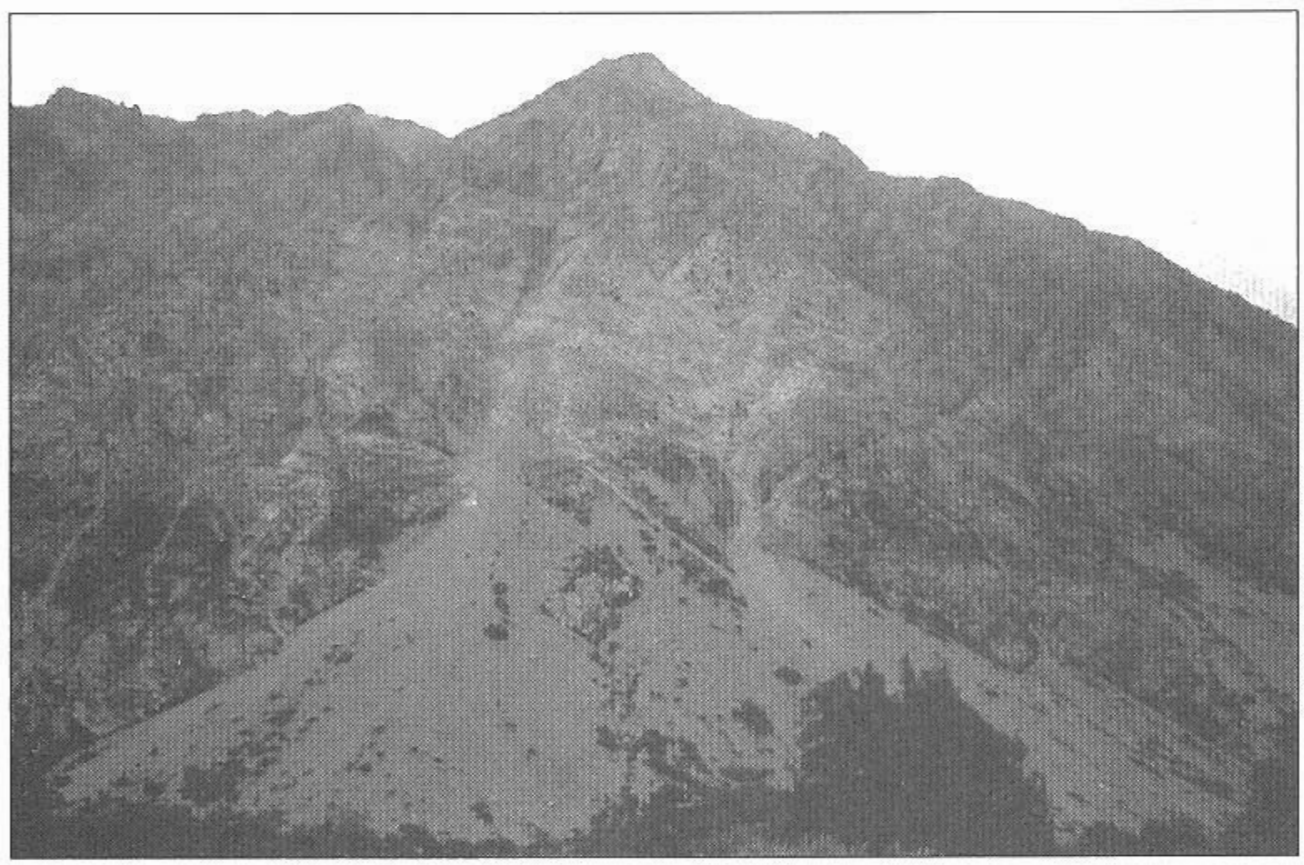

Flanco de valle activo en sector de alta montaña: Conos funcionales de escombros ordenados al pie de laderas sometidas estacionalmente a mecanismos periglaciales. Son alimentados por desprendimiento de material detrítico desde rocas sedimentariovolcánicas altamente fracturadas, proceso que sufre variaciones estacionales de intensidad. 


\section{Imagen de Investigagiones GEOGRÁFICAS}

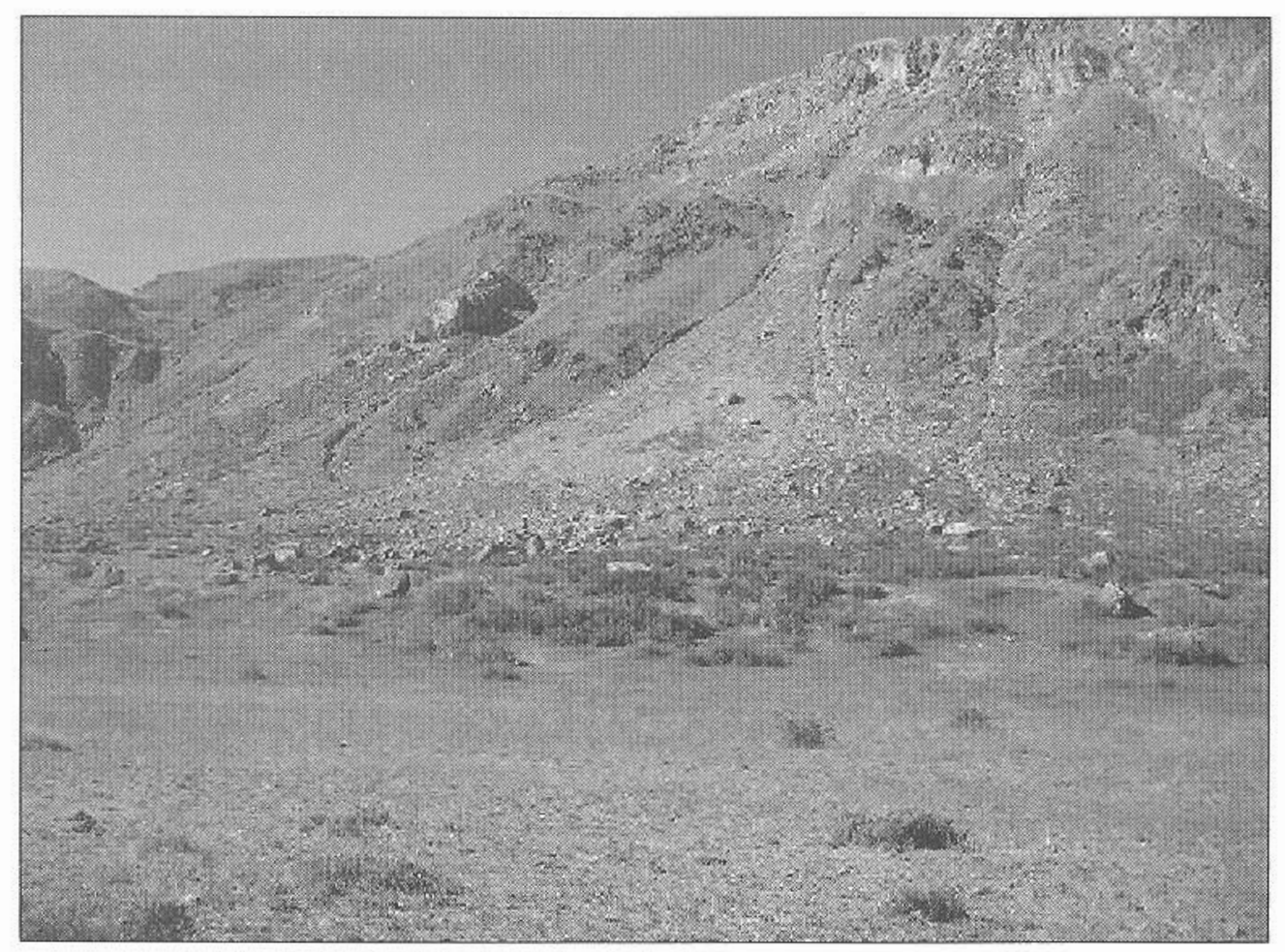

Cono de gravedad en Termas del Flaco, Andes de Chile central. Obsérvese los grandes bloques de la parte distal, indicando la zona de run-out. Fenómenos similares pueden ocurrir en el Paso Las Leñas, tratado en este número. Foto J. F. Araya-Vergara. 